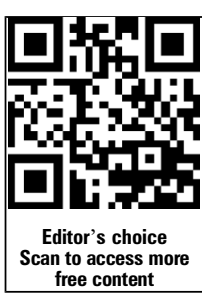
'Department of Respiratory
Medicine, Royal Prince Alfred Hospital, Sydney, New South Wales, Australia

${ }^{2}$ Sydney Medical School, University of Sydney, Sydney, New South Wales, Australia

${ }^{3}$ Ludwig Engel Centre for Respiratory Research,

Westmead Hospital, Sydney, New South Wales, Australia

${ }^{4}$ Centre for Asthma and Respiratory Diseases, Hunter Medical Research Institute, University of Newcastle and John Hunter Hospital,

Newcastle, New South Wales, Australia

${ }^{5}$ Faculty of Medicine and Health Sciences, Macquarie University, Sydney, New South Wales, Australia

\section{Correspondence to}

Dr Ruth L Dentice, Department of Respiratory Medicine, Level 11 E Block, Royal Prince Alfred Hospital, Sydney, NSW 2050, Australia;

ruth.dentice@sswahs.nsw.gov. au

Received 13 January 2015 Accepted 16 December 2015

\section{SLinked}

- http://dx.doi.org/10.1136/ thoraxjnl-2015-208057

\section{CrossMark}

$$
\begin{aligned}
& \text { To cite: Dentice RL, } \\
& \text { Elkins MR, Middleton PG, } \\
& \text { et al. Thorax 2016;71: }
\end{aligned}
$$$$
\text { 141-147. }
$$

\title{
A randomised trial of hypertonic saline during hospitalisation for exacerbation of cystic fibrosis
}

\author{
Ruth L Dentice, ${ }^{1,2}$ Mark R Elkins, ${ }^{1,2}$ Peter G Middleton, ${ }^{3}$ Jennifer R Bishop, ${ }^{3}$ \\ Peter A B Wark, ${ }^{4}$ Douglas J Dorahy, ${ }^{4}$ Christopher J Harmer, ${ }^{2}$ Honghua Hu, ${ }^{2,5}$ \\ Peter T P Bye ${ }^{1,2}$
}

\section{ABSTRACT \\ Background The mucoactive effects of hypertonic} saline should promote exacerbation resolution in people with cystic fibrosis (CF).

Objectives To determine the effects of hypertonic saline inhalation during hospitalisation for exacerbation of CF on length of stay, lung function, symptoms, oxygenation, exercise tolerance, quality of life, bacterial load and time to next hospitalisation.

Methods 132 adults with an exacerbation of CF were randomised to inhale three nebulised doses a day of either $4 \mathrm{~mL} 7 \%$ saline or a taste-masked control of $0.12 \%$ saline, throughout the hospital admission. The primary outcome measure was length of hospital stay. Results All participants tolerated their allocated saline solution. There was no significant difference in length of stay, which was 12 days in the hypertonic saline group and 13 days in controls, with a mean between-group difference (MD) of 1 day (95\% Cl 0 to 2). The likelihood of regaining pre-exacerbation $\mathrm{FEV}_{1}$ by discharge was significantly higher in the hypertonic saline group (75\% vs $57 \%)$, and the number needed to treat was $6(95 \%$ Cl 3 to 65$)$. On a 0-100 scale, the hypertonic saline group had significantly greater reduction in symptom severity than the control group at discharge in sleep ( $M D=13,95 \% \mathrm{Cl} 4$ to 23), congestion (MD=10,95\% $\mathrm{Cl} 3$ to 18) and dyspnoea (MD=8,95\% Cl 1 to 16). No significant difference in time to next hospitalisation for a pulmonary exacerbation was detected between groups $(\mathrm{HR}=0.86(\mathrm{Cl} 0.57$ to 1.30$), p=0.13)$. Other outcomes did not significantly differ.

Conclusions Addition of hypertonic saline to the management of a CF exacerbation did not reduce the length of hospital stay. Hypertonic saline speeds the resolution of exacerbation symptoms and allows patients to leave hospital with greater symptom resolution.

Trial registration number ACTRN12605000780651.

\section{INTRODUCTION}

Cystic fibrosis (CF) is the most common lifeshortening genetic disease in Caucasians. It is characterised by abnormal airway ion transport, which dehydrates the airway surface, impairing the clearance of airway secretions by cough and mucociliary clearance. ${ }^{1}$ The retention of airway secretions predisposes the patient to chronic lung infection, which leads to progressive lung damage and eventual respiratory failure. The progression of this pulmonary disease is characterised by irregular, acute

\section{Key messages}

What is the key question?

- Does hypertonic saline reduce length of stay, is it tolerable and does it hasten recovery if used during an exacerbation of cystic fibrosis lung disease?

\section{What is the bottom line?}

- For adults with cystic fibrosis during hospitalisation for an exacerbation, nebulised hypertonic saline does not reduce length of stay, but is tolerable, reduces symptom severity more rapidly and increases the likelihood of regaining pre-exacerbation lung function by discharge.

\section{Why read on?}

- This paper describes a hypertonic saline regimen that was tolerated during an exacerbation by both naïve and experienced users of hypertonic saline. Despite no statistically significant reduction in the primary outcome of length of stay, secondary benefits in exacerbation symptom resolution were demonstrated.

increases in pulmonary symptoms termed exacerbations, which are partly reversible. ${ }^{2}$ Exacerbations present clinically as deterioration in spirometry, cough, sputum production, dyspnoea, energy and appetite. In people with CF, long-term decline in respiratory function ${ }^{3}$ and exacerbation frequency ${ }^{4}$ predict mortality. Long-term lung function decline is slowed if pulmonary exacerbations are identified early and treated thoroughly to restore preexacerbation status. ${ }^{3}{ }^{5}$ Exacerbations also reduce the quality of life (QoL) of people with CF by reducing exercise capacity and disrupting school and work. ${ }^{6}$

In the short term, hypertonic saline (HS) improves the rheological properties and transportability of sputum, hydration of the airway surface, ${ }^{7}$ mucociliary clearance and lung function in people with $\mathrm{CF}^{8-10}$ Long-term use of HS improves lung function, QoL and ease of expectoration. ${ }^{11}$ Long-term HS treatment also shifts Pseudomonas aeruginosa subpopulations in the CF lung away 
from mucoid variants, which are strongly associated with increased morbidity, to non-mucoid strains. ${ }^{12}$ Also high salinity may affect $P$. aeruginosa motility ${ }^{13}$ and the viability of the mucoid subpopulation in biofilms. ${ }^{14}$

After clinical benefits from HS were established, ${ }^{9}{ }^{11}$ some clinicians elected to continue (or introduce) HS during an exacerbation, with the intention of shortening the exacerbation; promoting full restoration to pre-exacerbation status; and minimising the duration for which intravenous antibiotics are required, to discourage the development of resistant organisms. However, HS was known to induce cough and airway narrowing in some stable patients. ${ }^{8} 1115$ In view of this, some patients and/or clinicians elected to stop (or not introduce) HS inhalations during an exacerbation.

Therefore, this study was designed to examine the equipoise regarding whether $\mathrm{HS}$ is harmful or beneficial during standard inpatient management of a pulmonary exacerbation in adults with CF, with respect to tolerability, length of hospital stay (primary outcome), rate of resolution of clinical signs and symptoms of the exacerbation and time to next exacerbation.

\section{METHOD}

The trial protocol was prospectively registered (ACTRN12605000780651) and approved by the ethics committee at each site. Written, informed consent was obtained from all participants. Some study results have been reported in abstracts. $^{16} 17$

\section{Study design}

This randomised, placebo-controlled, parallel-group study compared nebulised $7 \%$ HS with a control of $0.12 \%$ saline, inhaled three times a day throughout a hospital admission for pulmonary exacerbation in adults with CF. The concealed randomisation process used minimisation to adaptively balance the active and control treatment allocations at each enrolment site. This process also ensured that randomisation was stratified for DNase use, $\mathrm{FEV}_{1}(\geq /<50 \%$ predicted on admission), gender and fall in $\mathrm{FEV}_{1}\left(\geq /<25 \%\right.$ fall from best outpatient $\mathrm{FEV}_{1}$ in the past 6 months). All participants, clinicians and investigators remained blinded to treatment group allocation throughout the study.

\section{Participants}

Adults with CF were recruited from Royal Prince Alfred Hospital, Westmead Hospital and John Hunter Hospital in New South Wales, Australia. Enrolment of participants occurred within $24 \mathrm{~h}$ of hospital admission. Inclusion criteria were a confirmed diagnosis of CF and admission for management of a pulmonary exacerbation (defined as at least 4 out of 12 criteria used by Fuchs et $a l^{18}$ ), for a minimum of 7 days. Exclusion criteria were major haemoptysis within the past year $(>250 \mathrm{~mL}$ in $24 \mathrm{~h}$ ); thrombocytopenia (platelets $<150 \times 10^{9} / \mathrm{L}$ ); allergy to quinine sulfate; glucose 6-phosphate dehydrogenase deficiency; immune thrombocytopenic purpura; pregnancy; breastfeeding; Burkholderia cepacia or mycobacteria ever isolated from the sputum; or lung transplant.

\section{Interventions}

Participants were randomly allocated to inhale either $4 \mathrm{~mL} \mathrm{7 \%}$ HS or $0.12 \%$ saline, three times a day via a jet nebuliser (Pari LC Star, Hamburg, Germany), throughout their hospital admission. Isotonic saline is an established control inhalation in clinical trials of HS. ${ }^{1} 111920$ Concentrations of $0.9 \%$ and $0.12 \%$ isotonic saline have a similar impact on mucociliary clearance. ${ }^{21}$
Quinine sulfate was used to disguise the difference in taste between hypertonic and control saline solutions, as successfully done in long-term trials of $\mathrm{HS}^{11}$ and other inhaled agents ${ }^{22}$ for people with CF, with no adverse side effects reported. Participants were instructed to use their usual bronchodilator as premedication before the first dose of their allocated saline solution. Participants who did not usually use a bronchodilator premedicated with $2 \times 100 \mu \mathrm{g}$ salbutamol sulfate via a metred dose inhaler (Glaxo Smith Kline, Australia) and a Volumatic spacer device (Glaxo Smith Kline, Australia). Change in $\mathrm{FEV}_{1}$ from before to after the first dose of bronchodilator and allocated saline solution was measured to ensure that any fall was $<15 \%$, brief and not associated with oxygen desaturation $<90 \%$. $^{11}$

\section{Usual care provided to both groups}

Upon admission to hospital, a daily routine of airway clearance physiotherapy and allocated saline solution was established by a blinded, experienced physiotherapist. The techniques were chosen for each participant according to perceived efficacy and participant preference and aligned with the recommended application of the selected techniques. ${ }^{23}$ All participants received intravenous antibiotic therapy decided by a blinded physician, review by a dietician, and other inhaled and oral therapies, as applicable. The day of discharge was decided based on lung function and symptoms (rather than a fixed duration of antibiotic therapy) by the usual CF physician who was blinded to the participants' group allocation.

\section{Outcomes}

The primary outcome was length of hospital stay in days. Secondary outcomes were the rate of change in lung function, measured as $\mathrm{FEV}_{1}$ and FVC via spirometry daily; symptom scores, measured on a $100 \mathrm{~mm}$ Visual Analogue Scale (VAS) daily; oxygenation, measured by pulse oximetry daily; exercise tolerance, measured by the modified shuttle test (MST-25) ${ }^{24}$ on admission and day 7; QoL, measured via the generic Medical Outcomes Survey Short Form $36(\mathrm{SF} 36)^{25}$ and the diseasespecific Cystic Fibrosis Questionnaire $(\mathrm{CFQ})^{26}$ on admission, day 7 and discharge; bacterial load, measured with quantitative microbiology on admission and day 7; and time to next hospitalisation for a pulmonary exacerbation, with minimum follow up of 1 year. Tolerability of the interventions was also assessed using a tolerability test on the first dose (described above) and adverse events.

\section{Data analysis}

Assuming a mean length of stay of 15 days (SD 4.2), 132 patients provide $83 \%$ power to identify a 2 -day reduction in length of stay as statistically significant. All analyses were by intention to treat. Time to next exacerbation was analysed as a HR calculated from Kaplan-Meier survival curves. Daily lung function, symptom severity and oxygenation were each analysed by mixed-model analysis with adjustment for baseline and no assumption of linearity. The mixed-model analyses used data from the first 10 days of hospitalisation because substantial numbers of participants began to be discharged thereafter. Restoration of pre-exacerbation $\mathrm{FEV}_{1}$ was defined dichotomously as reaching or exceeding the best recorded outpatient $\mathrm{FEV}_{1}$ in the 6 months before the exacerbation and analysed using relative risk. Other outcomes were compared using t tests after confirmation of normal distributions. Wherever possible, the statistical significance and precision of between-group comparisons were reported with 95\% CIs. Tests for interaction effects were conducted to determine whether use of HS before 
the exacerbation influenced the amount of benefit from HS during the hospitalisation on the following outcomes: length of stay and failure to regain pre-exacerbation $\mathrm{FEV}_{1}$. For these subgroup analyses, previous use was defined as regular or intermittent use.

\section{RESULTS}

The flow of participants through the study is shown in figure 1 . Enrolment began in December 2005 and was completed in 6 years, during which standard care did not substantially change. Follow-up of hospital readmissions finished in February 2013.

The baseline characteristics of participants are shown in table 1 .

\section{Tolerability and adherence}

No participants had an acute fall in either their $\mathrm{FEV}_{1}$ of $>15 \%$ or oxygen desaturation after their first dose of saline with salbutamol before treatment. Participants reported mild and transient increases in cough and wheeze that resolved within 15 min of inhalation. Median adherence to the inhalations was $100 \%$ in the HS group and $98 \%$ in the control group. Only $6 \%$ of the HS group and $14 \%$ of the control group were $<75 \%$ adherent to the allocated study inhalation. No serious adverse events occurred.

\section{Success of blinding}

After inhalation of the first dose of their allocation saline solution, $46 \%$ of participants in the HS group and $42 \%$ in the control group correctly identified their allocated trial solution.

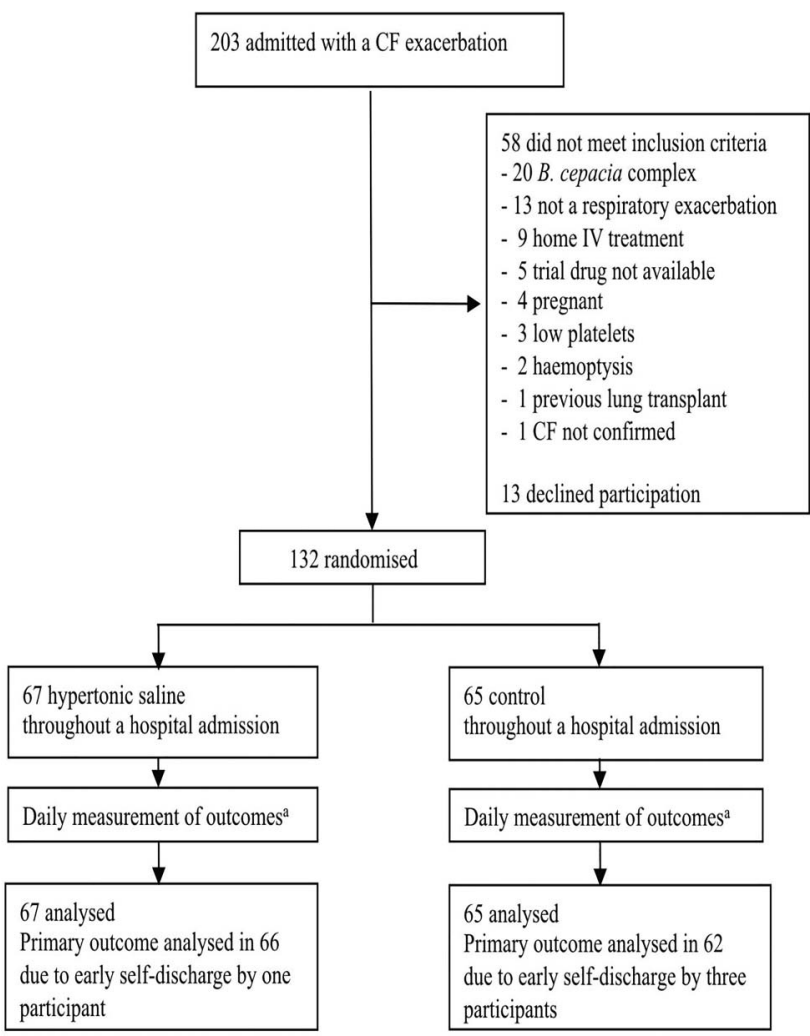

Figure 1 Screening, enrolment, randomisation and participation of subjects. ${ }^{a}$ Except exercise capacity (day 7 only) and sputum microbiology and quality of life (day 7 and discharge only). CF, cystic fibrosis.
On the day of hospital discharge $57 \%$ of participants in each group correctly identified their allocated trial solution.

\section{Primary outcome}

Length of stay was 12 days in the treatment group and 13 days in the control group, with a mean difference of 1 day (CI 0 to 2 ), $p=0.07$. The mean estimate of 1 day is below the 2-day difference nominated in the sample size calculation.

\section{Secondary outcomes}

Lung function

Both groups showed a steady improvement in lung function throughout their hospital admission. The HS group had a significantly higher $\mathrm{FEV}_{1}$ than the control group during the first 10 days of the hospital admission; mean difference $172 \mathrm{~mL}$ (CI 42 to 301), figure 2. At discharge, the difference in $\mathrm{FEV}_{1}$ between the groups was similar in magnitude but was not statistically significant. However, FVC was significantly higher in the HS group; mean difference $160 \mathrm{~mL}$ (CI 0 to 320), figure 3 . Participants were significantly more likely to have returned to their pre-exacerbation $\mathrm{FEV}_{1}$ at discharge in the treatment group $(75 \%)$ than the control group (57\%), table 2 . The relative risk presented in the table equates to a number needed to treat of 6 (CI 3 to 65).

\section{Symptoms}

On the mixed-model analyses of the symptom severity data (recorded daily on a $100 \mathrm{~mm}$ scale throughout the hospital admission), the HS group had significantly greater improvement than the control group in sleep disturbance by $15 \mathrm{~mm}$ (CI 6 to 23), chest congestion by $9 \mathrm{~mm}$ (CI 4 to 14) and dyspnoea by $6 \mathrm{~mm}$ (CI 1 to 12). The improvement favoured the treatment group for fatigue by $8 \mathrm{~mm}$ (CI 0 to 15) and cough by $6 \mathrm{~mm}$ (CI 0 to 11$)$. At discharge, compared with the control group, the treatment group had significantly less severe sleep disturbance

Table 1 Demographic and clinical characteristics of the 132 participants on admission

\begin{tabular}{|c|c|c|}
\hline Characteristics & $\begin{array}{l}\text { Hypertonic saline } \\
(n=67)\end{array}$ & $\begin{array}{l}\text { Control } \\
(n=65)\end{array}$ \\
\hline Age (years) & $28 \pm 9(17-62)$ & $27 \pm 9(18-63)$ \\
\hline Gender, $\mathrm{n}$ female (\%) & $35(52)$ & $30(46)$ \\
\hline BMI $\left(\mathrm{kg} / \mathrm{m}^{2}\right)$ & $21 \pm 3(15-32)$ & $21 \pm 3(15-29)$ \\
\hline $\mathrm{FEV}_{1}$ (\% predicted) & $49 \pm 22(10-94)$ & $47 \pm 19(16-88)$ \\
\hline FVC (\% predicted) & $70 \pm 21(25-118)$ & $67 \pm 19(26-110)$ \\
\hline $\mathrm{FEF}_{25-75}(\%$ predicted $)$ & $24 \pm 20(2-96)$ & $21 \pm 16(3-88)$ \\
\hline $\begin{array}{l}\text { Fall in } \mathrm{FEV}_{1} \text { with exacerbation } \\
\text { from best outpatient value in the } \\
\text { past } 6 \text { months ( } \% \text { fall) }\end{array}$ & $18 \pm 16(8-63)$ & $18 \pm 15(19-59)$ \\
\hline $\begin{array}{l}>25 \% \text { fall in } \mathrm{FEV}_{1} \text { with } \\
\text { exacerbation, } \mathrm{n}(\%)\end{array}$ & $18(27)$ & $15(23)$ \\
\hline Exacerbation score (/12) & $7 \pm 2(4-11)$ & $7 \pm 1(4-10)$ \\
\hline Modified shuttle test (metres) & $737 \pm 354(30-1500)$ & $726 \pm 266(270-1390)$ \\
\hline Regular rhDNase use, $\mathrm{n}(\%)$ & $37(55)$ & $39(60)$ \\
\hline Regular HS use, n (\%) & $14(21)$ & $11(17)$ \\
\hline Intermittent HS use*, n (\%) & $26(39)$ & $28(43)$ \\
\hline No or minimal HS use, $\mathrm{n}(\%)$ & $27(40)$ & $26(40)$ \\
\hline
\end{tabular}




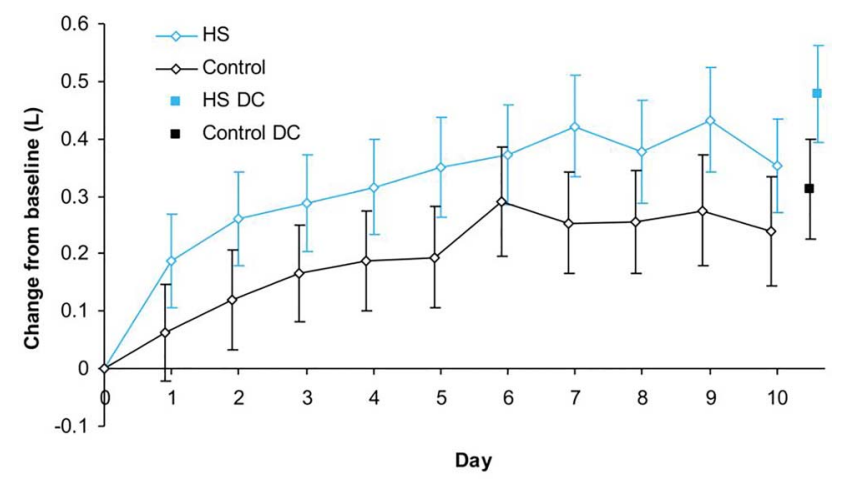

Figure 2 Mixed-model analysis for change from baseline in $\mathrm{FEV}_{1}$ for day/group interaction. Mean difference during admission to day 10 was $172 \mathrm{~mL}(\mathrm{Cl} 42$ to 301). Mean difference at discharge was $170 \mathrm{~mL}(\mathrm{Cl}$ -70 to 410 ). Daily means and SEs are shown. DC, discharge; HS, hypertonic saline.

by $13 \mathrm{~mm}$ (CI 4 to 23), chest congestion by $10 \mathrm{~mm}$ (CI 3 to 18 ) and dyspnoea by $8 \mathrm{~mm}$ (CI 1 to 16). The daily VAS for chest congestion is illustrated in figure 4 .

\section{Oxygenation and exercise capacity}

Both groups showed steady improvement in oxygenation throughout the admission, with no significant difference between the groups on the mixed-model analysis (not shown). Similarly, exercise capacity improved substantially in both groups between admission and day 7 , with no significant difference between the groups, table 3 .

\section{Quality of life}

Comparison of group means for relevant domains of the SF36 and CFQ were made at day 7 and at discharge with tests adjusted for baseline covariates and Bonferroni corrected. No significant differences between the groups were identified, table 3 . The change from baseline in the physical domain of the SF36 at day 7 and discharge was the only QoL domain to demonstrate a trend, which was in favour of HS.

\section{Quantitative microbiology}

Both groups showed a reduction in the density of both $P$. aeruginosa and Staphylococcus aureus between hospital admission and day 7 (in the participants who were able to provide a sputum

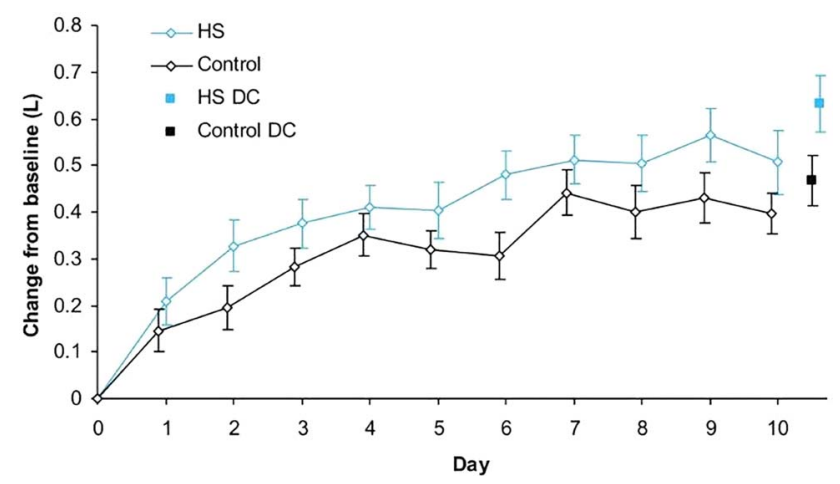

Figure 3 Mixed-model analysis for change from baseline in FVC for day/group interaction. Mean difference during admission to day 10 was $66 \mathrm{~mL}(\mathrm{Cl}-56$ to 188). Mean difference at discharge was $160 \mathrm{~mL}$ (Cl 0 to 320). Daily means and SEs are shown. DC, discharge; HS, hypertonic saline.
Table 2 Number and proportion of trial participants in each group who failed to regain their pre-exacerbation $\mathrm{FEV}_{1}$, with relative risk $(95 \% \mathrm{Cl})$ due to hypertonic saline use

\begin{tabular}{llll}
\hline Characteristic & $\begin{array}{l}\text { Hypertonic } \\
\text { saline } \\
(\mathbf{n}=67)\end{array}$ & $\begin{array}{l}\text { Control } \\
(\mathbf{n}=65)\end{array}$ & $\begin{array}{l}\text { Relative risk } \\
(95 \% \mathrm{Cl})\end{array}$ \\
\hline $\begin{array}{l}\text { Failed to regain } \\
\text { pre-exacerbation } \mathrm{FEV}_{1} \text { by } \\
\text { discharge, } \mathrm{n}(\%)\end{array}$ & $17(25)$ & $28(43)$ & 0.59 (0.36 to 0.96) \\
\hline
\end{tabular}

Pre-exacerbation $\mathrm{FEV}_{1}$ is defined as the best forced expiratory volume in $1 \mathrm{~s}$ recorded as an outpatient in the 6 months before the exacerbation.

sample at baseline for analysis). Both groups had participants who were positive for $P$. aeruginosa on admission who were negative on day 7: $10 \%$ in the hypertonic and 6\% in the control group. Clearance of $S$. aureus was higher in both groups: $25 \%$ in the hypertonic group and $24 \%$ in the control group. These data are summarised in table 3 .

Time to next hospitalisation for a pulmonary exacerbation

No significant difference in time to next exacerbation requiring hospitalisation was detected between groups; $\mathrm{HR}=0.86$ (CI 0.57 to 1.30 ), figure 5 .

Tests for interaction effects

The tests for interaction effects due to pre-exacerbation use of HS were non-significant: $p=0.06$ for length of stay and $p=0.42$ for failure to regain pre-exacerbation $\mathrm{FEV}_{1}$.

\section{DISCUSSION}

The inhalation of HS three times daily during hospitalisation for an acute pulmonary exacerbation in adults with CF did not have a significant impact on hospital length of stay compared with the inhalation of control saline. The HS group remained in hospital for a mean of 12 days (SD 3.3) compared with the control group who remained in hospital for a mean of 13 days (SD 3.1): mean difference 1 day (95\% CI 0 to 2$) ; p=0.07$. In this trial, the standard care received by both groups included intravenous antibiotics and multidisciplinary management by a CF team. This effective regimen makes it difficult for any additional treatment to produce further benefits.

The inhalation of HS was well tolerated in the presence of an acute exacerbation of CF lung disease. Despite the addition of



Figure 4 Mixed-model analysis for change from baseline in chest congestion (Visual Analogue Scale in $\mathrm{mm}$ ) for day/group interaction. Mean difference during admission to day 10 was $9 \mathrm{~mm}(\mathrm{Cl} 4$ to 14). Mean difference at discharge was $10 \mathrm{~mm}$ (Cl 3 to 18). Daily means and SEs are shown. DC, discharge; HS, hypertonic saline. 
Table 3 Group mean change from hospital admission for quality of life (day 7 and discharge), exercise tolerance and sputum microbiology (day 7)

\begin{tabular}{|c|c|c|c|c|c|c|}
\hline \multirow[b]{2}{*}{ Outcome } & \multicolumn{3}{|c|}{ Change from admission to day 7} & \multicolumn{3}{|c|}{ Change from admission to discharge } \\
\hline & $\begin{array}{l}\text { Hypertonic } \\
\text { saline } \\
(n=67) \\
\text { Mean } \pm S D\end{array}$ & $\begin{array}{l}\text { Control } \\
(n=65) \\
\text { Mean } \\
\pm S D\end{array}$ & $\begin{array}{l}\text { Between-group } \\
\text { difference } \\
\text { Mean }(\mathrm{CI})\end{array}$ & $\begin{array}{l}\text { Hypertonic } \\
\text { saline } \\
(n=67) \\
\text { Mean } \pm S D\end{array}$ & $\begin{array}{l}\text { Control } \\
(n=65) \\
\text { Mean } \\
\pm S D\end{array}$ & $\begin{array}{l}\text { Between-group } \\
\text { difference } \\
\text { Mean }(\mathrm{Cl})\end{array}$ \\
\hline \multicolumn{7}{|l|}{ SF36 (0-100) } \\
\hline Physical & $11 \pm 18$ & $7 \pm 13$ & $4(-1$ to 9$)$ & $13 \pm 19$ & $9 \pm 19$ & $4(-2$ to 10$)$ \\
\hline General health & $5 \pm 12$ & $5 \pm 13$ & $0(-4$ to 4$)$ & $7 \pm 11$ & $8 \pm 16$ & $-1(-6$ to 4$)$ \\
\hline Vitality & $7 \pm 15$ & $6 \pm 12$ & $2(-3$ to 6$)$ & $11 \pm 20$ & $13 \pm 15$ & -1 (-7 to 4$)$ \\
\hline \multicolumn{7}{|l|}{ CFQ (0-100) } \\
\hline Physical & $11 \pm 16$ & $9 \pm 14$ & $2(-4$ to 7$)$ & $16 \pm 19$ & $14 \pm 17$ & $3(-4$ to 9$)$ \\
\hline Burden & $0 \pm 14$ & $0 \pm 14$ & $-1(-6$ to 4$)$ & $1 \pm 15$ & $-1 \pm 20$ & $1(-4$ to 7$)$ \\
\hline Health & $12 \pm 19$ & $14 \pm 17$ & -2 (-8 to 4$)$ & $20 \pm 21$ & $18 \pm 20$ & $2(-5$ to 10$)$ \\
\hline Respiratory & $13 \pm 19$ & $12 \pm 16$ & $1(-5$ to 7$)$ & $19 \pm 21$ & $21 \pm 18$ & $-2(-8$ to 5$)$ \\
\hline MST-25 (0-100) & $166 \pm 138$ & $120 \pm 210$ & $46(-19$ to 110$)$ & & & \\
\hline \multicolumn{7}{|c|}{ Bacterial density $\left(\log _{10} \mathrm{CFU} / \mathrm{g}\right)$} \\
\hline $\begin{array}{l}\text { Pseudomonas } \\
\text { aeruginosa }\end{array}$ & $-0.8 \pm 2.2$ & $-1.1 \pm 2.2$ & $0.2(-0.6$ to 1.1$)$ & & & \\
\hline Staphylococcus aureus & $-0.4 \pm 1.4$ & $-0.8 \pm 1.6$ & $0.4(-0.8$ to 1.6$)$ & & & \\
\hline
\end{tabular}

three inhalations a day to the hospital treatment regimen, the questionnaire domains related to treatment burden were unchanged compared with baseline. Adherence levels were high with only $6 \%$ of the HS group and $14 \%$ of the control group $<75 \%$ adherent to the allocated study inhalation. Very few modifications to the trial inhalations were required and no serious adverse events were recorded. These findings suggest that the inhalation of HS as part of the management of an acute exacerbation of CF lung disease is both well tolerated and feasible in clinical practice.

Both groups showed a steady improvement in lung function throughout their hospital admission. The HS group had a significantly higher $\mathrm{FEV}_{1}$ than the control group during the first 10 days of the hospital admission, by $172 \mathrm{~mL}$ (CI 42 to 301), which equated to $3 \%$ predicted (CI $1 \%$ to $6 \%$ ). Although the magnitude of the between-group difference in $\mathrm{FEV}_{1}$ was similar at hospital discharge, this difference was not statistically

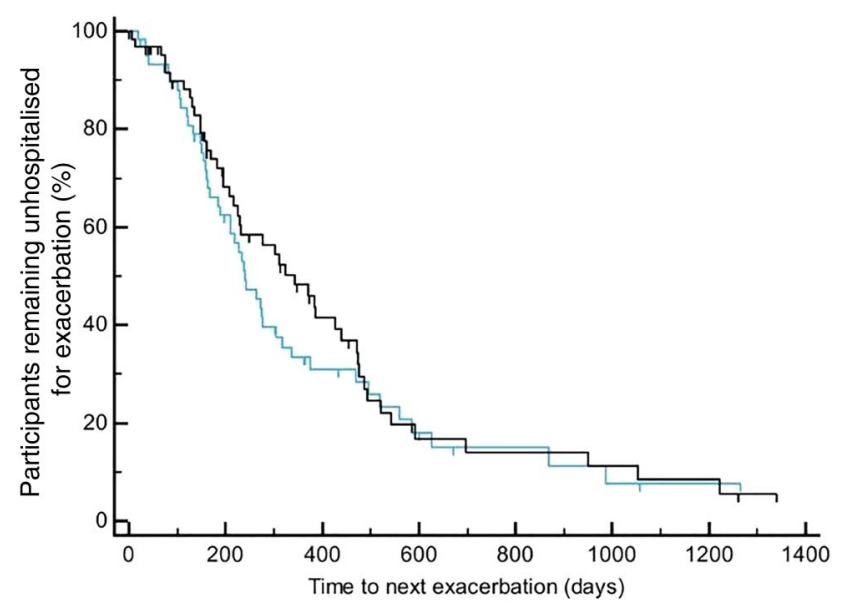

Figure 5 Time to next pulmonary exacerbation requiring hospitalisation. Hypertonic saline is presented in blue, control in black $(p=0.48)$. Censored cases are represented as vertical tick marks. significant. This may be because the result at discharge is based on a t test, which has less statistical power than the mixedmodel analysis of the first 10 days of data. Both mean values exceed the $150 \mathrm{~mL}$ threshold used in a previous study in a similar patient population as the between-group difference in $\mathrm{FEV}_{1}$ that would be likely to make a change in treatment worthwhile. $^{27}$ The HS group had a significantly higher FVC than the control group at discharge; mean difference $160 \mathrm{~mL}$ (CI 0 to 320). This suggests that the average impact on lung function in this study would make the addition of HS inhalations to the management of an exacerbation worthwhile.

A significantly smaller proportion of participants in the HS group failed to regain their pre-exacerbation $\mathrm{FEV}_{1}$ by discharge; $25 \%$ in the HS group and $43 \%$ in the control group. This finding is of interest because the long-term rate of lung function decline is minimised if pulmonary exacerbations are identified early and treated thoroughly to achieve full restoration of preexacerbation $\mathrm{FEV}_{1} \cdot{ }^{3}{ }^{5}$ Furthermore, reported rates of failure to regain pre-exacerbation $\mathrm{FEV}_{1}$ with hospitalisation range from $25 \%$ to $36 \% .^{28-31}$ The higher failure rate in our control group may reflect the withdrawal of HS from those in the placebo group who previously used it. However, this was not supported by the non-significance of the tests for interaction effects. Another possible explanation is the greater age and disease severity of our study cohort compared with the cohorts in the previous studies. ${ }^{28-31}$ In either case, HS afforded a significant treatment advantage. Thus, for every six patients who use HS during an admission (CI 3 to 65), one additional patient would regain their pre-exacerbation $\mathrm{FEV}_{1}$ who would not do so without HS. Therefore starting or continuing HS during an exacerbation is more beneficial than stopping or not starting it.

For a similar or slightly shorter length of hospital stay, participants in the HS group left hospital with greater reductions in the severity of exacerbation symptoms, evident on a mixedmodel analysis over the first 10 days of the admission.

Although no significant difference in QoL was detected, the HS group tended to have greater improvements in the physical domain of the SF36 at day 7 and discharge. The observed trend 
towards greater improvements in exercise tolerance in the HS group supports this observation.

Although use of HS led to faster rates of recovery of objective and subjective aspects of an exacerbation, and the greater likelihood of regaining pre-exacerbation $\mathrm{FEV}_{1}$, by the time of discharge from hospital, the treatment did not extend the time to the next hospitalisation for pulmonary exacerbation, based on a minimum of 1 -year follow-up, $\mathrm{HR}=0.86$ (CI 0.57 to 1.30 ).

One limitation of the trial is that the clinical status of the participants was not monitored after discharge. However, if there were differences in clinical status, these were not sufficient to influence time to next hospitalisation owing to an exacerbation. Another limitation is that tests for viral infection as a potential initiator of the exacerbation were not conducted at baseline. Some people may also consider that the enrolment of people who were already using HS was a study limitation. However, this view would be based on the assumption that HS must be beneficial during an exacerbation, perhaps based on extrapolation of the data from long-term use started when the patient is clinically stable. ${ }^{11}$ However, as discussed in the 'Introduction', before this study there was substantial equipoise regarding whether HS should or should not be used during an exacerbation. The arguments behind this equipoise were equally relevant to pre-existing HS users and non-users. This equipoise was reinforced during the study when objective data confirmed the potential for HS use during an exacerbation to worsen symptoms in some patients, ${ }^{32}$ reinforcing the need for the study to allow for the possibility that withdrawal of HS during an exacerbation might be beneficial. Therefore, the inclusion of people who were already using HS was not a study limitation, but a necessary part of the study design. Furthermore, our negative tests for interaction effects demonstrate that it is appropriate to pool those data of pre-existing users and non-users to conclude that use of HS during an exacerbation has some benefits, regardless of pre-existing HS use.

The use of taste masking to blind participants to their allocated inhalation was effective in this study. However in both groups the percentage of participants who could correctly identify their allocated trial solution rose to $57 \%$ at the time of hospital discharge. Possibly, the rate of improvement in symptoms contributed to this observation.

\section{CONCLUSION}

The addition of HS to the management of a CF exacerbation did not reduce the length of hospital stay. Regular HS inhalation during an acute exacerbation is well tolerated, well adhered to and feasible in clinical practice. HS has a significant impact on the resolution of symptoms of CF exacerbations. Inpatients were able to be discharged with significantly greater resolution of several subjective and objective measures of their exacerbation and with improved likelihood that they would regain their preexacerbation lung function by the day of discharge. Further research is required to determine whether the beneficial effects on restoration of lung function and resolution of exacerbation symptoms have an impact on the length of stay in other hospitals.

Acknowledgements We thank Rob Herbert, Anne-Sophie Aubriot, Lucy Keatley, Lesley Howard and Vanessa McDonald for their contributions to the study.

Contributors RLD: hypothesis and design, acquisition of data, analysis and interpretation, manuscript preparation. MRE: conception, hypothesis and design, acquisition of data, analysis and interpretation, manuscript preparation. PGM, JRB: participant recruitment, acquisition of data, revision of manuscript. PABW: participant recruitment, revision of manuscript. DJD: participant recruitment, acquisition of data. CJH, HH: data acquisition and analysis, revision of manuscript.
PTPB: conception, hypothesis and design, analysis and interpretation, revision of manuscript.

Funding This study was supported by the National Health and Medical Research Council Cooperative Centre for Research Excellence in Respiratory and Sleep Medicine postgraduate research scholarship and the US Cystic Fibrosis Foundation grant BYE04AO.

Competing interests None declared.

Ethics approval Ethics review committee (Royal Prince Albert Hospital zone) of the Sydney South West Area Health Service.

Provenance and peer review Not commissioned; externally peer reviewed.

Data sharing statement This randomised controlled trial is reported in full in RLD's PhD thesis (The University of Sydney, 2012).

\section{REFERENCES}

1 Boucher RC. Airway surface dehydration in CF: pathogenesis and therapy. Annu Rev Med 2007:58:157-70.

2 Flume PA, Mogayzel PJJ, Robinson KA, et al. Cystic fibrosis pulmonary guidelines: treatment of pulmonary exacerbations. Am J Respir Crit Care Med 2009; 180:802-8.

3 Liou T, Adler F, FitzSimmons S, et al. Predictive 5-year survivorship model of cystic fibrosis. Am J Epidemiol 2001;153:345-52.

4 de Boer $\mathrm{K}$, Vandemheen $\mathrm{KL}$, Tullis $\mathrm{E}$, et al. Exacerbation frequency and clinical outcomes in adult patients with cystic fibrosis. Thorax 2011;66:680-5.

5 Waters V, Stanojevic S, Atenafu E, et al. Effect of pulmonary exacerbations on long term lung function decline in cystic fibrosis. Eur Respir J 2012;40:61-6.

6 Yi MS, Tsevat J, Wilmott RW, et al. The impact of treatment of pulmonary exacerbations on the health-related quality of life of patients with cystic fibrosis: does hospitalization make a difference? J Pediatr 2004;144:711-18.

7 Tarran R, Grubb BR, Parsons D, et al. The CF salt controversy: in vivo observations and therapeutic approaches. Mol Cell 2001;8:149-58.

8 Robinson M, Hemming AL, Regnis JA, et al. Effect of increasing doses of hypertonic saline on mucociliary clearance in patients with cystic fibrosis. Thorax 1997; 52:900-3

9 Eng PA, Morton J, Douglass JA, et al. Short-term efficacy of ultrasonically nebulized hypertonic saline in cystic fibrosis. Pediatr Pulmonol 1996;21:77-83.

10 Robinson M, Regnis JA, Bailey DL, et al. Effect of hypertonic saline, amiloride and cough on mucociliary clearance in patients with cystic fibrosis. Am J Respir Crit Care Med 1996:153:1503-9.

11 Elkins MR, Robinson M, Rose BR, et al. A controlled trial of long-term inhaled hypertonic saline in patients with cystic fibrosis. N Engl J Med 2006;354:229-40.

12 Williams HD, Behrends V, Bundy JG, et al. Hypertonic saline therapy in cystic fibrosis: do population shifts caused by the osmotic sensitivity of infecting bacteria explain the effectiveness of this treatment? Frontiers Microbiol 2010;1:120.

13 Havasi V, Hurst CO, Briles TC, et al. Inhibitory effects of hypertonic saline on $P$. aeruginosa motility. J Cyst Fibros 2008;7:267-9.

14 Behrends V, Ryall B, Wang $X$, et al. Metabolic profiling of Pseudomonas aeruginosa demonstrates that the anti-sigma factor MucA modulates osmotic stress tolerance. Mol Biosyst 2010;6:562-9.

15 Wark P, McDonald V, Jones AP. Nebulised hypertonic saline for cystic fibrosis. Cochrane Datab Syst Rev 2005;3:CD001506.

16 Dentice R, Elkins M, Middleton P, et al. A randomised controlled trial of the effect of hypertonic saline (HS) inhalation on exacerbation resolution, hospital length of stay and time to relapse in adults with cystic fibrosis. J Cyst Fibros 2013;12(S1):S38

17 Dentice $R$, Elkins $M$, Middleton $P$, et al. A randomised trial of hypertonic saline nebulisation during hospitalisation for pulmonary exacerbations in adults with cystic fibrosis. Pediatr Pulmonol 2012;S35:257.

18 Fuchs HJ, Borowitz DS, Christiansen DH, et al. Effect of aerosolized recombinant human DNase on exacerbations of respiratory symptoms and on pulmonary function in patients with cystic fibrosis. The Pulmozyme Study Group. N Engl J Med 1994;331:637-42.

19 Wark P, McDonald V. Nebulised hypertonic saline for cystic fibrosis. Cochrane Datab Syst Rev 2009:2:CD001506.

20 Laube B, Sharpless G, Carson K, et al. Acute inhalation of hypertonic saline does not improve mucociliary clearance in all children with cystic fibrosis. BMC Pulm Med 2011;11:45.

21 Sood N, Bennett WD, Zeman K, et al. Increasing concentration of inhaled saline with or without amiloride: effect on mucociliary clearance in normal subjects. Am J Respir Crit Care Med 2003;167:158-63.

22 Ramsey BW, Pepe MS, Quan JM, et al. Intermittent administration of inhaled tobramycin in patients with Cystic Fibrosis. N Engl J Med 1999;340:23-30.

23 Mcllwaine MP, Van Ginderdeuren F, eds. Physiotherapy for people with cystic fibrosis: from infant to adult. 4th edn. International Physiotherapy Group for Cystic Fibrosis, 2009.

24 Elkins MR, Dentice RL, Bye PT. Reliability and repeatability of the MST-25: an extension of the Modified Shuttle Test (MST). Pediatr Pulmonol 2009;44(S32):369, A445. 
25 Ware J, Sherbourne C. The MOS 36-item short-form health survey: conceptual framework and item selection. Med Care 1992;30:473-81.

26 Quittner AL, Sweeny S, Watrous M, et al. Translation and linguistic validation of a disease-specific quality of life measure for cystic fibrosis. J Pediatr Psychol 2000;25:403-14.

27 Dentice R, Elkins M, Bye P. Adults with cystic fibrosis prefer hypertonic saline before or during airway clearance techniques: a randomised crossover trial. J Physiother 2012;58:33-40.

28 Sanders $\mathrm{DB}$, Bittner RC, Rosenfeld $\mathrm{M}$, et al. Failure to recover to baseline pulmonary function after cystic fibrosis pulmonary exacerbation. Am J Respir Crit Care Med 2010;182:627-32.
29 Sanders DB, Hoffman LR, Emerson J, et al. Return of FEV1 after pulmonary exacerbation in children with cystic fibrosis. Pediatr Pulmonol 2010;45:127-34.

30 Sanders DB, Bittner RC, Rosenfeld M, et al. Pulmonary exacerbations are associated with subsequent FEV1 decline in both adults and children with cystic fibrosis. Pediatr Pulmonol 2011;46:393-400.

31 Leonard W, Zobell JT, Ensign R, et al. Retrospective evaluation of appropriate duration of intravenous antibiotic therapy for acute cystic fibrosis exacerbations. Pediatr Pulmonol 2011;36(S34):331.

32 Pezzulo A, Stoltz D, Hornick D, et al. Inhaled hypertonic saline in adults hospitalised for exacerbation of cystic fibrosis lung disease: a retrospective study. BMJ Open 2012;2:e000407. 